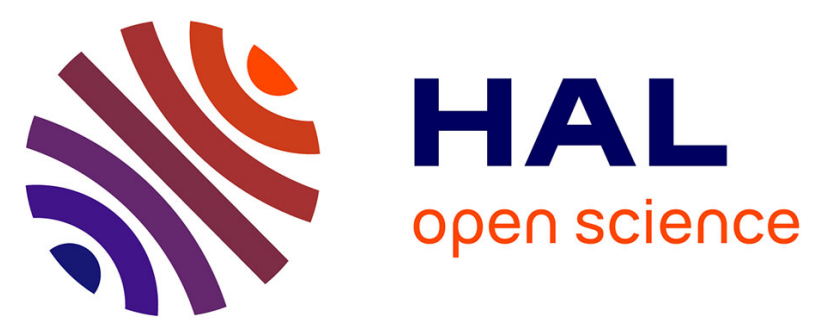

\title{
The effect of cycling followed by running on respiratory muscle performance in elite and competition triathletes
}

Alain Boussana, Olivier Hue, Stefan Matecki, Olivier Galy, Michèle Ramonatxo, Alain Varray, Daniel Le Gallais

\section{- To cite this version:}

Alain Boussana, Olivier Hue, Stefan Matecki, Olivier Galy, Michèle Ramonatxo, et al.. The effect of cycling followed by running on respiratory muscle performance in elite and competition triathletes. European Journal of Applied Physiology, 2002, 87, pp.441-447. 10.1007/s00421-002-0637-x . hal00720562

\section{HAL Id: hal-00720562 https://hal.univ-antilles.fr/hal-00720562}

Submitted on 24 Jul 2012

HAL is a multi-disciplinary open access archive for the deposit and dissemination of scientific research documents, whether they are published or not. The documents may come from teaching and research institutions in France or abroad, or from public or private research centers.
L'archive ouverte pluridisciplinaire HAL, est destinée au dépôt et à la diffusion de documents scientifiques de niveau recherche, publiés ou non, émanant des établissements d'enseignement et de recherche français ou étrangers, des laboratoires publics ou privés. 


\title{
A. Boussana $\cdot$ O. Hue $\cdot$ S. Matecki $\cdot$ O. Galy \\ M. Ramonatxo · A. Varray · D. Le Gallais \\ The effect of cycling followed by running on respiratory muscle performance in elite and competition triathletes
}

\author{
Accepted: 3 April 2002 / Published online: 25 June 2002 \\ (C) Springer-Verlag 2002
}

\begin{abstract}
This study investigated the possibility of there being differences in respiratory muscle strength and endurance in elite and competition triathletes who have similar maximal oxygen uptakes $\left(\dot{V} \mathrm{O}_{2 \max }\right)$ and ventilatory thresholds $\left(\mathrm{Th}_{\mathrm{vent}}\right)$. Five internationally-ranked elite, [mean (SD) age 23.8 (1.4) years] and six nationallyand regionally-ranked competition [age 21.1 (1.1) years] male triathletes performed two successive trials: first an incremental cycle test to assess $\dot{V} \mathrm{O}_{2 \max }$ and $\mathrm{Th}_{\text {vent }}$ and second 20 min of cycling followed by 20 min of running (C-R) at intensities higher than $85 \% \dot{V} \mathrm{O}_{2 \max }$. Cardioventilatory data were collected every minute during the two trials, using an automated breath-by-breath system. Maximal expiratory and inspiratory $\left(P_{I \max }\right)$ strength were assessed before and $10 \mathrm{~min}$ after $\mathrm{C}-\mathrm{R}$ from the functional residual capacity. Respiratory muscle endurance was assessed 1 day before and $30 \mathrm{~min}$ after C-R by measuring the time limit $\left(t_{\mathrm{lim}}\right)$. The results showed firstly that during $\mathrm{C}-\mathrm{R}$, the competition triathletes had significantly $(P<0.05)$ higher minute ventilation [mean (SEM) $107.4(3.1)$ compared to $\left.99.8(3.7) 1 \cdot \mathrm{min}^{-1}\right]$, breathing frequency [44.4 (2.0) compared to
\end{abstract}

\footnotetext{
A. Boussana · O. Galy · A. Varray · D. Le Gallais $(\triangle)$

Unité Propre à l'Enseignement Supérieur Equipe d'Accueil 2991, Laboratoire Sport Performance Santé,

Faculté des Sciences du Sport,

700 Avenue du Pic Saint Loup,

34090 Montpellier, France

E-mail: d.legallais@staps.univ-montp1.fr

Tel.: + 33-04-67415732

Fax: +33-04-67415708

O. Hue

Laboratoire, Adaptation Climat Tropical et Exercice,

Unite de Formation et de Recherche en Sciences et

Techniques des Activités Physiques et Sportives,

Campus de Fouillole BP 592,

97159 Pointe à Pitre, Cedex, France

S. Matecki · M. Ramonatxo

Laboratoire de Physiologie des Interactions,

Centre Hospitalier Universitaire Arnaud

de Villeneuve, 34295 Montpellier,

Cedex 5, France
}

$\left.40.2(3.4) \cdot \mathrm{min}^{-1}\right]$ and heart rate [166 (3) compared to 159 (4) beats $\mathrm{min}^{-1}$ ] and secondly that after C-R, they had significantly lower $P_{\text {Imax }}[127.1$ (4.2) compared to $\left.130.7(3.0) \mathrm{cmH}_{2} \mathrm{O}\right]$ and $\mathrm{t}_{\lim }[2: 35(0: 29)$ compared to 4:12 $(0: 20) \mathrm{min}]$ than the elite triathletes. We conclude that, despite similar $\dot{V} \mathrm{O}_{2 \max }$ and $\mathrm{Th}_{\text {vent }}$, the competition triathletes showed less extensive adaptive mechanisms, including those in the respiratory muscles, than did the elite triathletes. This led to higher ventilation, which appeared to be the cause of the faster development of fatigue in the inspiratory muscles in this group.

Keywords Triathlon $\cdot$ Training Performance level $\cdot$ Respiratory muscles $\cdot$ Endurance time

\section{Introduction}

A recent study showed that training induces a beneficial effect not only in skeletal muscles, but also in respiratory muscles (Powers et al. 1997). Coast et al. (1990) compared highly trained cross-country skiers and untrained subjects after performing maximal exhausting cycle ergometer exercise and showed that maximal inspiratory pressure decreased in the untrained subjects, but not in the trained athletes. They suggested that the endurance exercise training undertaken by the skiers had induced an adaptive change in the inspiratory muscles that protected them from the acute loss of strength seen in normal subjects following exercise. Similarly, Bender and Martin (1985) compared trained runners and nonrunners after exhausting treadmill exercise lasting either 3-10 min or $60 \mathrm{~min}$, and showed that respiratory muscle endurance assessed by maximal voluntary ventilation (MVV) was more significantly decreased in the nonrunners than in the trained runners. Interestingly, the authors noted that during the $60 \mathrm{~min}$ run, the runners were ventilating similarly to (mean of minute ventilation, $\dot{V}_{\mathrm{E}}$, measurements taken every $10 \mathrm{~min}$ ) or relatively more (expression of mean exercise $\dot{V}_{\mathrm{E}}$ as a percentage of body mass) than the non-runners. In a recent study, 
Hue et al. (2000) reported significantly higher ventilatory responses during an experiment in which cycling was followed by running in competition triathletes, i.e. regionally- and nationally-ranked compared with elite triathletes, i.e. internationally-ranked. The authors concluded that the ventilatory response to exercise may have been related to the level of performance in the triathletes. We thus hypothesized that the higher ventilatory responses reported in competitive triathletes during exercise might signal respiratory muscle fatigue in these subjects (Boutellier 1998; Mador and Acevedo 1991). To verify this hypothesis, we employed a new, standardized, and reproducible method of quantifying endurance in respiratory muscles using a controlled breathing technique (Matecki et al. 2001).

The aim of the present study was to compare the effects of cycling followed by running, similar to that performed during a triathlon, on ventilatory responses and respiratory muscle strength and endurance in two groups of triathletes having different levels of performance. We hypothesized that the competition group would experience less extensive adaptive and endurance mechanisms in their respiratory muscles than would the elite groups, in spite of similar maximal oxygen uptakes $\left(\dot{V} \mathrm{O}_{2 \max }\right)$ and ventilatory threshholds $\left(\mathrm{Th}_{\mathrm{vent}}\right)$.

\section{Methods}

\section{Subjects}

Five internationally-ranked male triathletes (elite) who had been chosen to represent France in the Triathlon Union World Championship and six nationally- and regionally-ranked male triathletes (competition) (Table 1) participated in this study. They were informed of the purpose of the study and gave written consent before participating in the protocol, which had been approved by the local Ethics Committee. All were students at the School of Physical Education at the University of Montpellier, France, and members of the university athletic team, which has been the French national champion university in the triathlon for 5 consecutive years. The subjects had been competing in the triathlon for several years (range 4-10) and were in the competition period at the time of the study. No triathlete had a prior history of respiratory or cardiovascular disease.

\section{Spirometer tests}

Forced expiratory volume in $1 \mathrm{~s}$, forced vital capacity, residual volume and total lung capacity were measured using plethysmography
(Sensor Medics, Anaheim, Calif.) according to standard techniques and procedures. Lung volumes and expiratory flows were compared with reference values (American Thoracic Society 1986) to assure that the responses of all the triathletes were within normal values.

\section{Respiratory muscle strength}

Maximal expiratory $\left(P_{\text {Emax }}\right)$ and inspiratory $\left(P_{\operatorname{Imax}}\right)$ pressures at functional residual capacity (FRC) and the inspiratory load, mouth pressure $\left(P_{\mathrm{m}}\right)$, maintained were obtained using a Validyne MP45 transducer $\left( \pm 300 \mathrm{cmH}_{2} \mathrm{O}\right.$; model MP 45, Validyne Corp., Northridge, Calif.), and a CD 15 carrier demodulator. The athletes were asked to make a maximal expiratory or inspiratory effort against an occluded airway according to the method described by Black and Hyatt (1969). Using this method, the $P_{\text {Emax }}$ and $P_{\text {Imax }}$ manoeuvres were held for $1 \mathrm{~s}$ according to standard criteria. Repeated measurements were made until three technically satisfactory and reproducible measurements had been obtained (variation in $P_{\text {Emax }}$ or $P_{\text {Imax }}$ of less than $10 \%$ ) (Hayot et al. 2001). The reported data represent the best value for each athlete.

\section{Respiratory muscle endurance}

Respiratory muscle endurance was measured by assessing the time limit $\left(t_{\text {lim }}\right)$ using a standardized method of controlled breathing (Matecki et al. 2001). This $t_{\text {lim }}$ measurement has been demonstrated to be reproducible (Matecki et al. 2001). Briefly, $t_{\text {lim }}$ represents the maximal time a subject can breath against a predetermined inspiratory submaximal load (Roussos et al. 1979). During this experiment, a threshold valve was connected to the inspiratory side of the respiratory system, as previously described (Nikerson and Keens 1982). This valve consisted of a Plexiglas cylinder containing a spring-loaded poppet valve (Threshold Inspiratory Muscle Trainer, Healthscan Products, Cedar Grove, N.J.). When the negative pressure inside the cylinder exceeded the predetermined pressure load, the inspiratory orifice situated at the bottom of the cylinder would open, allowing inspiratory flow. The spring adjustment of this valve allowed us to impose $75 \%$ of the athlete's $P_{\text {Imax }}$ at FRC at each inspiration (Ker and Schultz 1996). The $P_{\mathrm{m}}$, which represented this imposed inspiratory load, was constant for a given adjustment of the threshold valve and was nearly flow-independent once the orifice was open (Johnson et al. 1996). Tidal volume $\left(V_{\mathrm{T}}\right)$ was obtained by integration of the flow signal. A volume signal was displayed as visual feedback to the subject on a storage oscilloscope to facilitate control of $V_{\mathrm{T}}$ during the required manoeuvre. Concomitantly, a beep was produced by an electronic metronome as auditory feedback. The subject was asked to inspire and expire at each beep. All signals were displayed on a Gould ES1000 recorder (Gould Inc., Cleveland, Ohio). Ten respiratory cycles were measured at rest and then at the beginning and end of the $t_{\text {lim }}$ measurement; this allowed us to calculate the following: inspiratory time $\left(t_{\mathrm{i}}\right)$, total time of the respiratory cycle $\left(t_{\mathrm{tot}}\right)$, ratio of inspiratory time to total time of the respiratory cycle $\left(t_{\mathrm{i}}: t_{\mathrm{tot}}\right)$, and imposed $P_{\mathrm{m}}$ The beginning of $t_{\mathrm{i}}$ was determined from the $P_{\mathrm{m}}$ signal, and the end

Table 1. Mean (SE) general characteristics, training regimen data and years of triathlon practice for both groups of male triathletes. Training distance was averaged during the period of the study

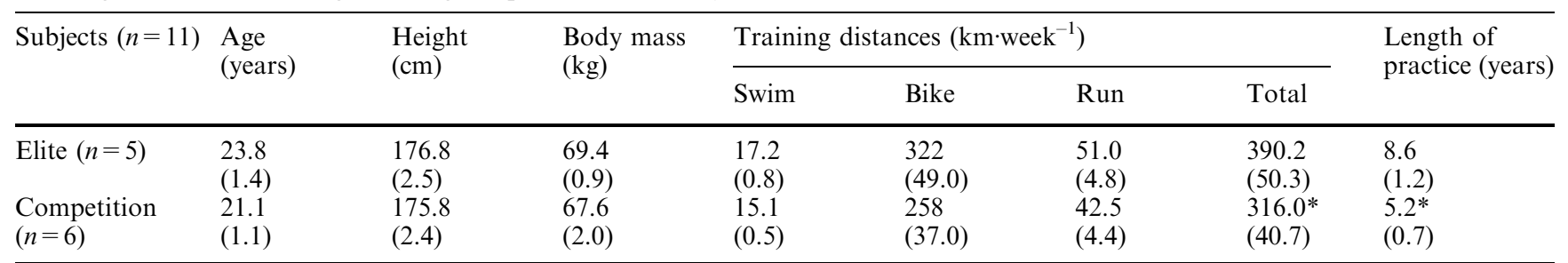

$* P<0.05$ Significant difference between groups 
was determined from the flow signal. Two parallel lines were drawn on the oscilloscope screen, with the distance between the two corresponding to the $V_{\mathrm{T}}$ imposed during the test at $700 \mathrm{ml}$ (Zocchi et al. 1993). The electronic metronome rate was $30 \cdot \mathrm{min}^{-1}$, to reproduce the total time of the respiratory cycle at rest $\left(t_{\text {tot,rest }}=4 \mathrm{~s}\right)$ with $t_{\mathrm{i}}: t_{\text {tot }}=0.5$. The subject then breathed, wearing a nose-clip, through the unloaded respiratory system while seated and at rest. When a steady state had been obtained, a screen was placed in front of him. He was asked to control his inspiratory volume in such a way as to keep the curve generated on the oscilloscope between the two lines at each breath. The electronic metronome was then started and the subject had to start inspiration at the first beep, control his inspiratory volume, and expire at the following beep. When a controlled breathing pattern at rest had been obtained for ten consecutive respiratory cycles, loaded breathing was started by adding the threshold valve to the inspiratory side at a threshold pressure of $75 \%$ of the $P_{\text {Imax }}$ determined for each individual. The athlete was asked to achieve a target inspiratory volume that corresponded to his $700 \mathrm{ml} V_{\mathrm{T}}$ at each inspiration while following the beeps and receiving verbal encouragement. The loaded breathing was continued until the subject could no longer maintain the target volume for three consecutive breaths or until he could no longer tolerate the procedure and rejected the mouthpiece. The length of the period of loaded breathing was defined as $t_{\text {lim }}$.

\section{Test protocols}

All subjects took part in two protocols. The tests were conducted in an air-conditioned laboratory having a mean room temperature of $21.9(0.2)^{\circ} \mathrm{C}$ and a barometric pressure of $777.5(4.5) \mathrm{mmHg}$. All tests were performed at the same time of day and on the same day of the week to minimize the influences of circadian rhythm and personal training on the study. The triathletes were asked to maintain their training schedules for the duration of the study but they were not allowed to compete in a triathlon during the period of the tests. In addition, they were asked to refrain from training on the days of the experiments. All athletes were familiarized with treadmill running and with the use of the cycle ergometer prior to the tests. Trial 1 consisted of an incremental cycle test (CE) performed on an electromagnetic cycle ergometer (Monark 864, Monark-Crescent AB, Varburg, Sweden). After a 3 min warm-up at $30 \mathrm{~W}$, the power was then increased by $30 \mathrm{~W}$ every minute until the subject was exhausted. Trial 2 consisted of $20 \mathrm{~min}$ of cycling followed by $20 \mathrm{~min}$ of running (C-R). Cycling was performed by the triathletes using their own cycle equipped with a handlebar on a home trainer (Pro Trainer, P.T., Milan, Italy). The intensity and gear ratio were close to the triathlete's performance level, above the $\mathrm{Th}_{\mathrm{vent}}$ calculated in trial 1 , and higher than $85 \%$ of $V \mathrm{O}_{2 \max }$, an exercise intensity which has been found to induce fatigue of the diaphragm (Johnson et al. 1993). The cycling speed was reached in less than $1 \mathrm{~min}$ and the oxygen uptake $\left(V \mathrm{O}_{2}\right)$ level was reached approximately at the $3 \mathrm{rd}$ min. Triathletes then adjusted their cycling speed by $1 \mathrm{~km} \cdot \mathrm{h}^{-1}$ each minute to optimize their cycling time performances. Distances were read from an odometer (Top Bike, Tokyo, Japan) on the bicycle. At the end of the 20 min of cycling, the subjects had $1 \mathrm{~min}$ to change their shoes and get on the treadmill (Gymroll 1800, Gymroll, Roche la Molière, France). The appropriate running speed was reached in less than $1 \mathrm{~min}$ and the $\mathrm{VO}_{2}$ level was reached approximately at the $3 \mathrm{rd} \mathrm{min}$. The triathletes then adjusted their running speed by $0.5 \mathrm{~km} \cdot \mathrm{h}^{-1}$ each minute to optimize their running time performance. Running distances were read from the treadmill odometer. As reported in a previous study (Hue et al. 1999), the cycling and running $V \mathrm{O}_{2 \max }$ values of the present group of triathletes were similar. Consequently, the $\mathrm{CE}$ $\dot{V} \mathrm{O}_{2 \max }$ value measured in trial 1 was used to monitor both the cycling and running intensities during C-R. Spirometer tests were made at rest before incremental $\mathrm{CE}$. Respiratory muscle strength was measured before and $10 \mathrm{~min}$ after C-R. Lastly, respiratory muscle endurance was measured 1 day before and 30 min after $\mathrm{C}-\mathrm{R}$. The endurance was measured 1 day before $\mathrm{C}-\mathrm{R}$ because Laghi et al. (1995) showed that fatigue of the diaphragm remained for at least $24 \mathrm{~h}$ in subjects who had breathed against inspiratory resistive loads of $60 \%$ of maximal transdiaphragm pressure.

\section{Gas exchange measurements}

Ventilatory data were measured every minute using a mass spectrometer breath-by-breath automated system (MGA-1100, Marquette, N.Y.): $\dot{V}_{\mathrm{E}}$ (litres per minute), $\dot{V} \mathrm{O}_{2}$ (millilitres per minute, millilitres per kilogram per minute), carbon dioxide production $\left(\dot{V} \mathrm{CO}_{2}\right.$, millilitres per minute), respiratory exchange ratio $(R)$, respiratory equivalents for $\mathrm{O}_{2}\left(\dot{V}_{\mathrm{E}} / \dot{V} \mathrm{O}_{2}\right)$ and $\mathrm{CO}_{2}\left(\dot{V}_{\mathrm{E}} / \dot{V} \mathrm{CO}_{2}\right)$, breathing frequency $\left(f\right.$, breaths per minute), and tidal volume $\left(V_{\mathrm{T}}\right.$, millilitres). Heart rate (HR, beats per minute) was measured using a telemetry system (Polar Sport Tester, Polar Electro Oy, Kempele, Finland). Trial 1 was performed to assess $\dot{V} \mathrm{O}_{2 \max }$ and $\mathrm{Th}_{\text {vent }}$ of the triathletes. The $\dot{V} \mathrm{O}_{2 \max }$ was determined according the following criteria:

1. Identification of a plateau in $\dot{V} \mathrm{O}_{2 \max }$ despite a further increase in power output

2. The HR equal to age-predicted maximal $\mathrm{HR} \pm 10$ beats $\min ^{-1}$

3. The $R \geq 1.10$

The $\mathrm{Th}_{\text {vent }}$ was automatically determined using the $V$-slope method of Beaver et al. (1986). This method involved the analysis of $\dot{V} \mathrm{CO}_{2}$ as a function of $\dot{V} \mathrm{O}_{2}$ and assumed that the $\mathrm{Th}_{\text {vent }}$ corresponded to the breakpoint in the $\dot{V} \mathrm{CO}_{2}-\dot{V} \mathrm{O}_{2}$ relationship.

\section{Statistical analysis}

The results are expressed as means (SE). Verification of a normal distribution was carried out for the general characteristics, $\dot{V}_{\mathrm{E}}$ during $\mathrm{C}-\mathrm{R}$, and the pre- minus post-C-R values of $P_{\text {Emax }}, P_{\text {Imax }}$, and $t_{\mathrm{lim}}$, of the competitive and elite triathlete groups. The $\dot{V} \mathrm{O}_{2 \max }$ during incremental $\mathrm{CE}$, then $\dot{V} \mathrm{O}_{2}$ and distance during $\mathrm{C}-\mathrm{R}$ and the cycling and running segments, were compared using a Student' $t$-test for two independent groups. Cardiopulmonary data during C-R: $\dot{V} \mathrm{O}_{2}, \dot{V}_{\mathrm{E}}, \dot{V}_{\mathrm{E}} / \dot{V} \mathrm{O}_{2}, \dot{V}_{\mathrm{E}} / \dot{V} \mathrm{CO}_{2}, f, R, V_{\mathrm{T}}$ and $\mathrm{HR}$ were compared between groups (competition compared to elite) and across exercise (C-R, then cycling and running) using a twoway analysis of variance (ANOVA). Values of respiratory muscle function $\left(P_{\text {Emax }}, P_{\text {Imax }}, t_{\text {lim }}\right)$ were compared pre-, post-C-R, and between groups using an ANOVA with repeated measures. Comparisons between groups were made by examination of the group xexercise interaction for the cardiopulmonary data and by the examination of the group $\times$ time interaction for the respiratory muscle function parameters. When $F$ values were significant, individual comparisons were made using the Scheffe's post-hoc test. The Spearman correlation coefficient was calculated between $\dot{V}_{\mathrm{E}}$ during C-R and the pre- minus post-C-R values of $P_{\text {Emax }}, P_{\text {Imax }}$, and $t_{\lim }$, for each group and all triathletes. Statistical analyses were performed using a computerized statistical software package (SYSTAT, International Thomson Publishing, Paris). Statistical significance was accepted at the $P<0.05$ level.

\section{Results}

No significant differences were noted in general characteristics (age, height, body mass, Table 1), $\dot{V} \mathrm{O}_{2 \max }$ [70.6 (1.9) $\mathrm{ml} \cdot \mathrm{kg}^{-1} \cdot \mathrm{min}^{-1}$ compared to $69.4(0.6) \mathrm{ml} \cdot \mathrm{kg}^{-1}$. $\left.\min ^{-1}\right]$ and $\mathrm{Th}_{\mathrm{vent}}\left[73.2(1.4) \% \dot{V} \mathrm{O}_{2 \max }\right.$ compared to $\left.67.7(4.1) \% \dot{V} \mathrm{O}_{2 \max }\right]$ for the elite and the competition triathletes, respectively. However, a significantly lower total quantity of training and significantly fewer years of triathlon practice were noted in the competition group compared to the elite group (Table 1). 
Exercise intensity

The two groups performed $\mathrm{C}-\mathrm{R}$ and the cycling and running segments at the same metabolic intensity, i.e. similar $\dot{V} \mathrm{O}_{2}$ and percentage of $\dot{V} \mathrm{O}_{2 \max }$. No significant differences in the distances of $\mathrm{C}-\mathrm{R}$ or the cycling and running segments were noted between the two groups (Table 2).

\section{Cardiopulmonary data}

During the cycle segment of C-R, $\dot{V}_{\mathrm{E}} f$ and HR were significantly higher in the competition compared to the elite group $(P<0.05)$. Similarly, during the running segment of C-R, $\dot{V}_{\mathrm{E}}, \dot{V}_{\mathrm{E}} / \dot{V} \mathrm{O}_{2}, \dot{V}_{\mathrm{E}} / \dot{V} \mathrm{CO}_{2}$, and $f$ were significantly higher in the competition group. Lastly, during C-R, $\dot{V}_{\mathrm{E}}, f$ and HR were significantly higher in the competition group (Table 2).

\section{Respiratory muscle strength}

The $P_{\text {Emax }}$ showed no significant difference pre- and post-C-R in either group or between groups (Fig. 1). The $P_{\text {Imax }}$ showed no significant difference pre- and post-C-R in the elite group, and a significant difference was noted between groups because of a significant decrease in $P_{\text {Imax }}$ pre- compared to post-C-R in the competition triathletes $(P<0.05)$ (Fig. 2).

\section{Respiratory muscle endurance}

The $t_{\lim }$ showed no significant difference pre-C-R between groups. In contrast, a significant decrease in $t_{\text {lim }}$

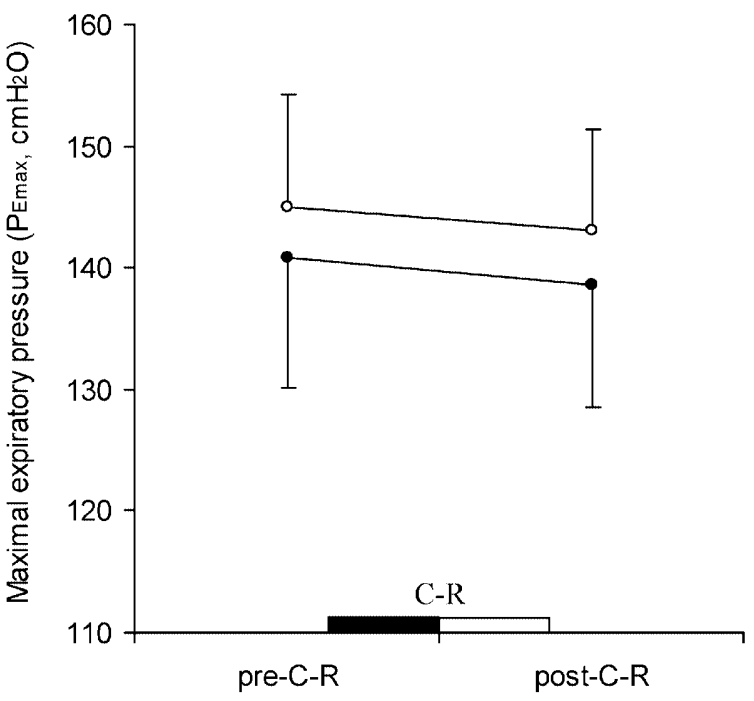

Fig. 1. Mean (SE) maximal expiratory pressure $\left(P_{\text {Emax }}\right)$ pre- $C-R$ and post-C-R (cycle-run succession) in elite (unfilled circles) and competition (filled circles) groups. No significant difference

was noted post-C-R in the two groups, with a significantly greater decrease in $t_{\lim }$ in the competition triathletes $(P<0.01)$ (Fig. 3).

Correlation between $\dot{V}_{\mathrm{E}}$ and respiratory muscle force and endurance

Individual data did not show a correlation between $\dot{V}_{\mathrm{E}}$ and fall in $P_{\text {Emax }}$ and $P_{\text {Imax }}$ in the competition or elite groups, or in all triathletes. In contrast, a significant correlation was found between individual $\dot{V}_{\mathrm{E}}$ data and fall in $t_{\text {lim }}$ for all triathletes (Fig. 4).
Table 2. Mean (SE) distance and cardioventilatory data during the cycle-run trial in competition and elite triathletes. ${ }^{\text {a }} P<0.05$ difference between groups during $\mathrm{C}-\mathrm{R}$, ${ }^{\mathrm{b}} P<0.05$ difference between groups in cycling segment of $\mathrm{C}-\mathrm{R},{ }^{\mathrm{c}} P<0.05$ difference between groups in running segment of $\mathrm{C}-\mathrm{R},{ }^{\mathrm{d}} \mathrm{P}<0.05$ difference between cycling and running in one group. $\dot{V} \mathrm{O}_{2}$ Oxygen uptake, $\dot{V}_{\mathrm{E}}$ minute ventilation, $\dot{V} \mathrm{CO}_{2}$ carbon dioxide production, $\dot{V}_{\mathrm{E}} / \dot{V} \mathrm{O}_{2}$ respiratory equivalent for $\mathrm{O}_{2}$, $\dot{V}_{\mathrm{E}} / \dot{V} \mathrm{CO}_{2}$ respiratory equivalent for $\mathrm{CO}_{2}, R$ respiratory exchange ratio, $f$ frequency of breathing, $V_{\mathrm{T}}$ tidal volume, $H R$ heart rate

\begin{tabular}{|c|c|c|c|c|c|c|}
\hline \multirow[t]{2}{*}{ Parameters } & \multicolumn{2}{|c|}{ Cycle-run } & \multicolumn{2}{|l|}{ Cycle } & \multicolumn{2}{|l|}{ Run } \\
\hline & Elite & Competition & Elite & Competition & Elite & Competition \\
\hline Distance $(\mathrm{km})$ & $\begin{array}{l}19.4 \\
(1.0)\end{array}$ & $\begin{array}{l}19.1 \\
(0.9)\end{array}$ & $\begin{array}{l}12.7 \\
(0.6)\end{array}$ & $\begin{array}{l}12.6 \\
(0.7)\end{array}$ & $\begin{array}{l}6.7^{\mathrm{d}} \\
(0.5)\end{array}$ & $\begin{array}{l}6.4^{\mathrm{d}} \\
(0.8)\end{array}$ \\
\hline$\dot{V} \mathrm{O}_{2}\left(\mathrm{ml} \cdot \mathrm{kg}^{-1} \cdot \mathrm{min}^{-1}\right)$ & $\begin{array}{l}62.7 \\
(2.0)\end{array}$ & $\begin{array}{l}61.7 \\
(1.8)\end{array}$ & $\begin{array}{l}62.0) \\
(1.9)\end{array}$ & $\begin{array}{l}63.8 \\
(2.0)\end{array}$ & $\begin{array}{l}62.8 \\
62.8 \\
(1.7)\end{array}$ & $\begin{array}{l}59.6 \\
(2.2)\end{array}$ \\
\hline$(\%)$ & $\begin{array}{l}88.9 \\
(1.9)\end{array}$ & $\begin{array}{l}89.0 \\
(2.0)\end{array}$ & $\begin{array}{l}88.4 \\
(1.9)\end{array}$ & $\begin{array}{l}92.1 \\
(2.1)\end{array}$ & $\begin{array}{l}89.0 \\
(2.0)\end{array}$ & $\begin{array}{l}86.1 \\
(3.3)\end{array}$ \\
\hline$\dot{V}_{\mathrm{E}}\left(1 \cdot \min ^{-1}\right)$ & 99.8 & $107.4^{\mathrm{c}}$ & $\begin{array}{l}88.0 \\
(4.7)\end{array}$ & $\begin{array}{l}98.2^{\mathrm{b}} \\
(4.5)\end{array}$ & $111.0^{\mathrm{d}}$ & $116.6^{\mathrm{cd}}$ \\
\hline$\dot{V} \mathrm{CO}_{2}\left(\mathrm{ml} \cdot \mathrm{min}^{-1}\right)$ & $\begin{array}{l}4,048 \\
(220)\end{array}$ & $\begin{array}{l}3,981 \\
(380)\end{array}$ & $\begin{array}{l}4,082 \\
(240)\end{array}$ & $\begin{array}{l}4,125 \\
(440)\end{array}$ & $\begin{array}{l}4,112 \\
(314)\end{array}$ & $\begin{array}{l}3,862 \\
(300)\end{array}$ \\
\hline$\dot{V}_{\mathrm{E}} / \dot{V} \mathrm{O}_{2}$ & $\begin{array}{l}22.9 \\
(1.3)\end{array}$ & $\begin{array}{l}25.7 \\
(1.3)\end{array}$ & $\begin{array}{l}20.3 \\
(1.1)\end{array}$ & $\begin{array}{l}22.7 \\
(0.7)\end{array}$ & $\begin{array}{l}25.5^{\mathrm{d}} \\
(1.2)\end{array}$ & $\begin{array}{l}28.8^{\mathrm{cd}} \\
(0.4)\end{array}$ \\
\hline$\dot{V}_{\mathrm{E}} / \dot{V} \mathrm{CO}_{2}$ & $\begin{array}{l}24.8 \\
(1.3)\end{array}$ & $\begin{array}{l}27.0 \\
(1.4)\end{array}$ & $\begin{array}{l}21.6 \\
(1.0)\end{array}$ & $\begin{array}{l}23.7 \\
(0.7)\end{array}$ & $\begin{array}{l}26.9^{d} \\
(1.3)\end{array}$ & $\begin{array}{l}30.3^{\mathrm{cd}} \\
(1.1)\end{array}$ \\
\hline$R$ & $\begin{array}{l}0.93 \\
(0.01)\end{array}$ & $\begin{array}{l}0.95 \\
(0.01)\end{array}$ & $\begin{array}{l}0.94 \\
(0.01)\end{array}$ & $\begin{array}{l}0.95 \\
(0.02)\end{array}$ & $\begin{array}{l}0.94 \\
(0.01)\end{array}$ & $\begin{array}{l}0.95 \\
(0.01)\end{array}$ \\
\hline$f$ (breaths $\cdot \min ^{-1}$ ) & $\begin{array}{l}40.2 \\
(3.4)\end{array}$ & $\begin{array}{l}44.4^{\mathrm{c}} \\
(2.0)\end{array}$ & $\begin{array}{l}33.8 \\
(2.2)\end{array}$ & $\begin{array}{l}37.6^{\mathrm{b}} \\
(1.1)\end{array}$ & $\begin{array}{l}46.6 \\
(2.7)\end{array}$ & $\begin{array}{l}51.2^{\mathrm{cd}} \\
(3.4)\end{array}$ \\
\hline$V_{\mathrm{T}}(\mathrm{ml})$ & $\begin{array}{l}2,514 \\
(103)\end{array}$ & $\begin{array}{l}2,487 \\
(107)\end{array}$ & $\begin{array}{l}2,635 \\
(154)\end{array}$ & $\begin{array}{l}2,672 \\
(154)\end{array}$ & $\begin{array}{l}2,394 \\
(175)\end{array}$ & $\begin{array}{l}2,302 \\
(149)\end{array}$ \\
\hline HR (beats. $\mathrm{min}^{-1}$ ) & $\begin{array}{l}159 \\
(4)\end{array}$ & $\begin{array}{l}166^{\mathrm{c}} \\
\text { (3) }\end{array}$ & $\begin{array}{l}148 \\
\text { (4) }\end{array}$ & $\begin{array}{l}160^{b} \\
\text { (3) }\end{array}$ & $\begin{array}{l}170^{d} \\
(4)\end{array}$ & $\begin{array}{l}172^{\mathrm{d}} \\
\text { (2) }\end{array}$ \\
\hline
\end{tabular}




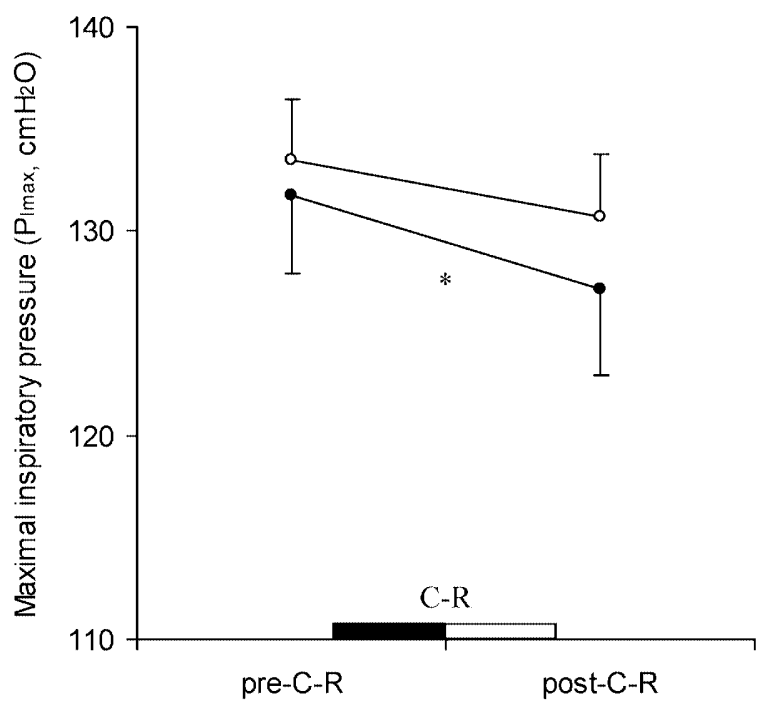

Fig. 2. Mean (SE) maximal inspiratory pressure $\left(P_{\text {Imax }}\right)$ pre- $C-R$ and post-C-R (cycle-run succession) in elite (unfilled circles) and competition (filled circles) groups. ${ }^{*} P<0.05$ between pre- and post-C-R values in competition group

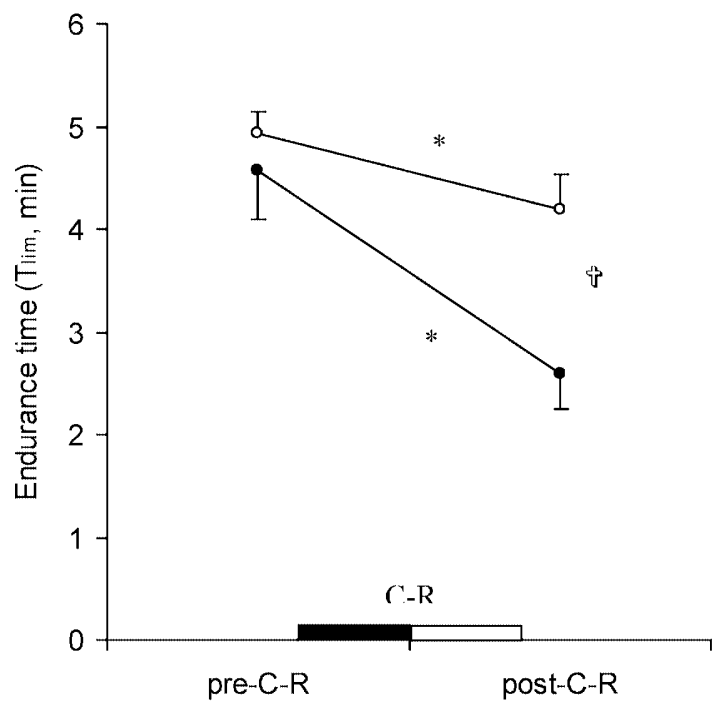

Fig. 3. Mean (SE) respiratory muscle endurance time $\left(T_{\lim }\right)$ pre- $C-R$ and post- $C-R$ (cycle-run succession) in elite (unfilledo circles) and competition (filled circles) groups. ${ }^{*} P<0.05$ between pre- and post$\mathrm{C}$ - $\mathrm{R}$ values. $\dagger P<0.05$ between post-C-R values in competition and elite groups

\section{Discussion}

The present study showed that cycling followed by running performed at similar metabolic intensities induced significantly higher ventilatory responses and a significantly greater decrease in respiratory muscle strength and endurance in competition than in elite triathletes.

The effect of exercise on expiratory muscle strength remains controversial. The literature has reported a

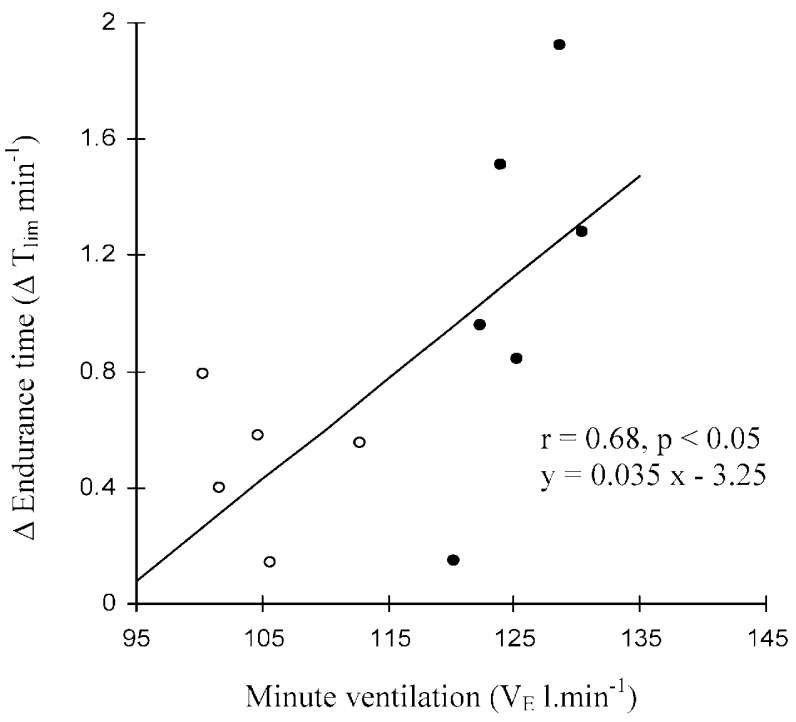

Fig. 4. Relationship between ventilation $\left(\dot{V}_{\mathrm{E}}\right)$ during C-R and difference $(\Delta)$ in respiratory muscle endurance time $\left(T_{\text {lim }}\right)$ at preand post-C-R (cycle-run succession). Elite (unfilled circles) and competition (filled circles) groups

significant decrease in $P_{\text {Emax }}$ after exercise in several studies (Cordain et al. 1994; Loke et al. 1982; O'Kroy et al. 1992), whereas other authors have failed to demonstrate this decrease (Chevrolet et al. 1993; Hill et al. 1991). The differences among the results may be due to differences in the protocols. The protocol of the present study was similar to those of O'Kroy et al. (1992) and Cordain et al. (1994), who failed to report impairment in $P_{\text {Emax }} 10$ min after submaximal exercise $(60 \%$ and $85 \% V \mathrm{O}_{2 \max }$ for 20 and $30 \mathrm{~min}$, respectively) in healthy men and conditioned recreational runners, respectively. This suggested that expiratory muscles are minimally involved during submaximal exercise. Heavy breathing would thus be a necessary condition for the development of fatigue in the expiratory muscles (Chevrolet et al. 1993). Hill et al. (1991) considered that fatigue in the expiratory muscles occurs only at exercise intensities above $\mathrm{Th}_{\text {vent }}$. The significantly higher $\dot{V}_{\mathrm{E}}$ recorded in the competition triathletes, the lack of correlation between $\dot{V}_{\mathrm{E}}$ and $P_{\text {Emax, }}$ and the lack of difference in $P_{\text {Emax }}$ between the competition and elite triathletes noted in our study reinforce the above hypothesis. However, because we measured $P_{\text {Emax }} 10$ min after C-R, we cannot exclude the possibility of a decrease in $P_{\text {Emax }}$ immediately after $\mathrm{C}-\mathrm{R}$ in one or both of the two groups of triathletes. Effectively, Cordain et al. (1994) reported a significant decrease in $P_{\text {Emax }}$ in healthy men 5 min after a submaximal exercise, with a return to normal 10 min later. Similarly, Suzuki et al. (1991) showed that expiratory muscle fatigue induced by high respiratory loading was reversed at the 15 th min of recovery. A significant decrease in $P_{\text {Emax }}$ was also reported $20-60 \mathrm{~min}$ after a marathon (Loke et al. 1982), whereas normal $P_{\text {Emax }}$ values were measured $2.5 \mathrm{~h}$ after completion of this race in a very similar study (Chevrolet et al. 1993). These 
observations suggest that expiratory muscles are involved during high intensity and long duration exercise. The rapid reverse in $P_{\text {Emax }}$ noted during recovery could have been due to the passive state of expiration during this period.

Inspiratory muscle strength was significantly decreased $10 \mathrm{~min}$ after $\mathrm{C}-\mathrm{R}$ in the competition but not in the elite triathletes. This suggested the appearance of fatigue in the inspiratory muscles in the competition triathletes (Johnson et al. 1993). The lack of correlation between individual $\dot{V}_{\mathrm{E}}$ data and the reduction in $P_{\text {Imax }}$ suggested that $\dot{V}_{\mathrm{E}}$ was not the only and/or the main mechanism involved in the decrease of $P_{\text {Imax }}$ in the competition triathletes. Hue et al. (2000) reported that significantly higher $\dot{V}_{\mathrm{E}}$ in competition triathletes corresponded to exercise-induced hypoxaemia. A $60 \% \dot{V} \mathrm{O}_{2 \max }$ intensity - corresponding approximately to the intensity yielding $\mathrm{Th}_{\mathrm{vent}}$ - during $30 \mathrm{~min}$ of treadmill running did not induce any decrease in $P_{\text {Imax }}$ in wellconditioned recreational runners (O'Kroy et al. 1992), whereas the same or a lower intensity during $12 \mathrm{~h}: 45$ min induced a decrease in $P_{\text {Imax }}$ in ultra-endurance triathletes (Hill et al. 1991). This observation showed that low intensity but long duration exercise leads to inspiratory muscle fatigue, even in well-trained athletes. This suggests that inspiratory muscles are involved, independently of the intensity of exercise. The measurement of $P_{\text {Imax }}$ following a marathon race showed that $P_{\text {Imax }}$ remained significantly decreased 20$60 \mathrm{~min}$ post-race (Loke et al. 1982), and again at $2.5 \mathrm{~h}$ of recovery from that race, in a very similar study (Chevrolet et al. 1993). This long duration of an impaired $P_{\text {Imax }}$ after exercise could be because inspiration is active during recovery. The comparison of $P_{\text {Imax }}$ in highly trained skiers compared to sedentary subjects after incremental exercise showed that endurance training induced an adaptive change in the inspiratory muscles that protected the skiers from the acute loss of strength seen following exercise in sedentary subjects (Coast et al. 1990). Similarly, McConnell et al. (1997) reported that extensive training enhanced inspiratory muscle strength and resistance in athletes. Although the current literature shows the effect of training on inspiratory muscle strength, the present study showed the effect of performance level on that variable: similar baseline values but a smaller deleterious effect after high intensity exercise with a higher performance level. This finding indicates that similar baseline inspiratory muscle strengths cannot predict the adaptation of $\dot{V}_{\mathrm{E}}$ and respiratory muscle strength during and after high intensity exercise, respectively.

The effect of exercise on maximal expiratory and inspiratory muscle strength thus appeared to be different. As shown in the literature, the inspiratory muscles have appeared to be more susceptible to fatigue and less capable of recovering from fatigue than the expiratory muscles. During exercise, inspiratory muscles are involved independently of intensity and duration of exercise, whereas expiratory muscles are involved only above the intensity of the $\mathrm{Th}_{\mathrm{vent}}$, and the duration of exercise appears less important. During recovery, inspiratory muscles continue to be involved, whereas expiratory muscles do not.

The giving of maximal expiratory and inspiratory muscle strength is not the main function of the respiratory muscles. We therefore tested respiratory muscle endurance. The present study showed that after exercise $t_{\text {lim }}$ was significantly decreased in both the competition and elite groups. However, the decrease in $t_{\text {lim }}$ was significantly greater in the competition triathletes, and a significant correlation was found between $\dot{V}_{\mathrm{E}}$ and $\Delta t_{\text {lim }}$ (pre- minus post-C-R $t_{\text {lim }}$ ) (Fig. 4). The decrease in respiratory muscle endurance reported after exercise in both groups of the present study is in agreement with findings in the literature. Loke et al. (1982) reported a decrease in MVV after completion of a marathon, Ker and Schultz (1996) noted a decrease in $t_{\lim } 3$ days after completion of an ultra-marathon, and Perret at al. (1999) reported a decrease in $\boldsymbol{t}_{\text {lim }}$ after a cycle test to exhaustion. Endurance of the respiratory muscles has been found to be related to exercise training. Martin and Stager (1981) reported greater endurance in athletes involved in sports requiring a high degree of aerobic fitness, in comparison with nonathletes. Fairbarn et al. (1991) showed that isocapnic hyperpnoea training increased respiratory muscle endurance in trained cyclists, in comparison with controls. On the other hand, Bender and Martin (1985) showed that after $60 \mathrm{~min}$ of exhausting exercise, nonrunners showed significantly lower respiratory muscle endurance than runners. In the present study, the competition group reported a significantly lower quantity of training and significantly fewer years of triathlon practice than the elite group. The competition triathletes displayed a greater decrease in $t_{\text {lim }}$, which was significantly correlated to $\dot{V}_{\mathrm{E}}$ during C-R. The higher $\dot{V}_{\mathrm{E}}$ recorded in the competition triathletes could have been due to a higher blood lactate concentration in relation to lactic anaerobic metabolism in locomotor muscles. The similar $\dot{V} \mathrm{CO}_{2}$ production and $R$ in the two groups allowed us to exclude this hypothesis. The higher $\dot{V}_{\mathrm{E}}$ recorded in the competition triathletes was also associated with higher $\dot{V}_{\mathrm{E}} / \dot{V} \mathrm{O}_{2}$, and $f$. Such higher ventilatory responses have been described in exerciseinduced hypoxaemia (EIH) (Caillaud et al. 1995; Préfaut et al. 1994) and respiratory muscle fatigue (Mador and Acevedo 1991; Hue et al. 2000). The EIH has been shown to occur in athletes competing at high level athletes more than in those at lower levels (Durand et al. 2000). We could thus exclude EIH. Finally, the higher $\dot{V}_{\mathrm{E}}$ recorded during C-R in the competition triathletes of the present study seemed to be due to less extensive adaptive mechanisms, including in the respiratory muscles, than in elite triathletes. This led us to suspect that the higher $\dot{V}_{\mathrm{E}}$ was the cause of the faster development of inspiratory muscle fatigue in the competition group. The current literature shows that trained athletes develop adaptive mechanisms that 
enhance their respiratory muscle endurance (Coast et al. 1990). Our data extend the previous findings to trained athletes with different performance levels.

In conclusion, the present study showed that competition triathletes displayed significantly higher ventilation during C-R, followed by a significant decrease in inspiratory muscle strength and a significantly greater decrease in respiratory muscle endurance after the exercise than elite triathletes with similar $\dot{V} \mathrm{O}_{2 \max }$ and $\mathrm{Th}_{\mathrm{vent}}$. One might therefore suggest that, despite this similar aerobic aptitude, the competition triathletes had not developed adaptive inspiratory and endurance mechanisms to the same extent as the elite triathletes, probably due to their lower quantity of training and/or fewer years of triathlon practice.

\section{References}

American Thoracic Society (1986) Evaluation of impairment/disability secondary to respiratory disorders. Am Rev Respir Dis 133:1205-1209

Beaver WL, Wasserman K, Whipp BJ (1986) A new method for detecting anaerobic threshold by gas exchange. J Appl Physiol 60:2020-2027

Bender PR, Martin BJ (1985). Maximal ventilation after exhausting exercise. Med Sci Sports Exerc 17:164-167

Black FL, Hyatt RE (1969) Maximal respiratory pressures: normal values and relationship to age and sex. Am Rev Respir Dis 99:696-702

Boutellier U (1998) Respiratory muscle fitness and exercise endurance in healthy humans. Med Sci Sports Exerc 30:11691172

Caillaud C, Serre-Cousine O, Anselme F, Capdevilla X, Préfaut C (1995) Computerized tomography and pulmonary diffusing capacity in highly trained athletes after performing a triathlon. J Appl Physiol 79:1226-1232

Chevrolet JC, Tschopp JM, Blanc Y, Rochat T, Junod AF (1993) Alterations in inspiratory and leg muscle force and recovery after marathon. Med Sci Sports Exerc 25:501-507

Coast RJ, Clifford PS, Henrich TW, Stray-Gundersen J, Johnson JR (1990) Maximal inspiratory pressure following maximal exercise in trained and untrained subjects. Med Sci Sports Exerc 22:811-815

Cordain L, Rode EJ, Gotshall RW, Tucker A (1994) Residual lung volume and ventilatory muscle strength changes following maximal and submaximal exercise. Int J Sports Med 15:158161

Durand F, Mucci P, Préfaut C (2000) Evidence for inadequate hyperventilation inducing arterial hypoxemia at submaximal exercise in all highly trained endurance athletes. Med Sci Sports Exerc 32:926-932

Fairbarn MS, Coutts KC, Pardy RL, McKenzie DC (1991) Improved respiratory muscle endurance of highly trained cyclists and the effects on maximal exercise performance. Int $\mathbf{J}$ Sports Med 12:66-70
Hayot M, Ramonatxo M, Matecki M, Milic-Emili J, Préfaut C (2001) Noninvasive assessment of inspiratory muscle function during exercise. Am J Respir Crit Care Med 162:2201-2207

Hill NS, Jacoby C, Farber HW (1991) Effect of an endurance triathlon on pulmonary function. Med Sci Sports Exrc 23:1260 1264

Hue O, Le Gallais D, Boussana A, Chollet D, Préfaut C (1999) Ventilatory responses during experimental cycle-run transition in triathletes. Med Sci Sports Exerc 31:1422-1428

Hue O, Le Gallais D, Boussana A, Chollet D, Préfaut C (2000) Performance level and cardiopulmonary response during a cycle-run trial. Int J Sports Med 21:250-255

Johnson DD, Babcock MA, Suman OE, Dempsey JA (1993) Exercise-induced diaphragmatic fatigue in healthy humans. J Physiol (Lond) 460:385-405

Johnson PH, Cowley AJ, Kinnear WJM (1996) Evaluation of the Threshold $\AA$ trainer for inspiratory muscle endurance training: comparison with the weighted plunger method. Eur Respir J 9:2681-2684

Ker JA, Schultz CM (1996) Respiratory muscle fatigue after an ultramarathon measured as inspiratory task failure. Int J Sports Med 17:493-496

Laghi F, D'Alfonso N, Tobin MJ (1995) Pattern of recovery from diaphragmatic fatigue over 24 hours. J Appl Physiol 79:539-546

Loke J, Mahler DA, Virgulto JA (1982) Respiratory muscle fatigue after marathon running. J Appl Physiol 52:821-824

Mador J, Acevedo FA (1991) Effect of respiratory muscle fatigue on breathing pattern during incremental exercise. Am Rev Respir Dis 143:462-468

Martin BJ, Stager JM (1981) Ventilatory endurance in athletes and non-athletes. Med Sci Sports Exerc 13:21-26

Matecki S, Topin N, Hayot M, Rivier F, Echenne B, Préfaut C, Ramonatxo M (2001) A standardized method for the evaluation of respiratory muscle endurance in patients with Duchenne muscular dystrophy. Neuromusc Disord 11:170-176

McConnell AK, Caine MP, Sharpe GR (1997) Inspiratory muscle fatigue following running to volitional fatigue: the influence of baseline strength. Int J Sports Med 18:169-173

Nickerson BG, Keens TG (1982) Measuring ventilatory muscle endurance in human as sustainable inspiratory pressure. J Appl Physiol 25:768-772

O'Kroy JA, Loy RA, Coast JR (1992) Pulmonary function changes following exercise. Med Sci Sports Exerc 24:1359-1364

Perret C, Pfeiffer R, Boutellier U, Wey HM, Spengler CM (1999) Noninvasive measurement of respiratory muscle performance after exhaustive endurance exercise. Eur Respir J 14:264-269

Powers SK, Coombes J, Demirel H (1997) Exercise training-induced changes in respiratory muscles. Sports Med 24:120-131

Préfaut C, Anselme F, Caillaud C, Masse-Biron J (1994) Exerciseinduced hypoxemia in older athletes. J Appl Physiol 76:120-126

Roussos C, Fixley M, Gross D, Macklem PT (1979) Fatigue of inspiratory muscles and their synergic behavior. J Appl Physiol 46:897-904

Suzuki S, Suzuki J, Okubo T (1991) Expiratory muscle fatigue in normal subjects. J Appl Physiol 70:2632-2639

Zocchi L, Fitting JW, Majani U, Fracchia C, Rampulla C, Grassino A (1993) Effect of pressure and timing of contraction on human rib cage muscle fatigue. Am Rev Respir Dis 147:857864 